\title{
Odontologia em Tempos de COVID-19: Revisão Integrativa e Proposta de Protocolo para Atendimento nas Unidades de Saúde Bucal da Polícia Militar do Estado do Rio de Janeiro - PMERJ
}

\begin{abstract}
Adriane Batista Pires Maia, ${ }^{1}$ Vanessa Paiva Reis, ${ }^{2}$ Adriana Raymundo Bezerra, ${ }^{3}$ Danielle Castex Conde ${ }^{4}$
${ }^{1}$ Serviço de Cirurgia e Traumatologia Bucomaxilofacial, Hospital Central da Polícia Militar (HCPM), PMERJ, Rio de Janeiro, RJ, Brasil

${ }^{2}$ Serviço de Cirurgia e Traumatologia Bucomaxilofacial, Policlínica da Polícia Militar de Cascadura (PPM-CASC), PMERJ, Rio de Janeiro, RJ, Brasil

${ }^{3}$ Serviço de Cirurgia e Traumatologia Bucomaxilofacial, Odontoclínica Central da Polícia Militar (OCPM), PMERJ, Rio de Janeiro, RJ, Brasil

${ }^{4}$ Serviço de Cirurgia e Traumatologia Bucomaxilofacial e Serviço de Anatomia Patológica do Hospital Central da Polícia Militar (HCPM), PMERJ, Rio de Janeiro, RJ, Brasil

- Conflito de interesse: nenhum declarado.
\end{abstract}

\section{Resumo}

Objetivo: sistematizar a produção bibliográfica sobre as recomendações, práticas e cuidados adotados no atendimento odontológico em tempos de COVID-19, assim como, propor um protocolo de atendimento odontológico nas unidades de saúde bucal da Polícia Militar do Estado do Rio de Janeiro a partir das evidências encontradas na literatura. Material e Métodos: foi realizada uma busca bibliográfica no dia 11 de abril de 2020 em bases bibliográficas eletrônicas brasileiras e internacionais (Portal Regional da Biblioteca Virtual em Saúde, Web of Science e Pubmed), a partir da estratégia de busca ("COVID-19" AND "dentistry"), entre estudos publicadas nos anos de 2019 e 2020. Após aplicados os critérios de inclusão e exclusão dos documentos, 18 estudos foram considerados elegíveis para a realização da revisão. Resultados: a partir das evidências científicas encontradas nos estudos, foi construída uma proposta de protocolo para o atendimento odontológico nas unidades de saúde da Polícia Militar do Estado do Rio de Janeiro, assim como em qualquer outra unidade de saúde bucal. Conclusão: durante o período de surto epidêmico os atendimentos devem restringir-se às urgências e emergências odontológicas. 0 Cirurgião-Dentista deve redobrar a atenção à rotina de biossegurança como: lavagem rigorosa das mãos com água e sabão e/ou 'álcool gel a 70\%', uso correto de todo equipamento de proteção individual e sua troca a cada paciente. Recomenda-se o tempo de 3 horas entre os atendimentos quando houver produção de aerossol, a higienização de todas as superfícies do consultório com hipoclorito de sódio a $0,1 \%$ ou 'álcool $70 \%$ ', esterilização de todo instrumental e o descarte adequado dos resíduos.

Palavras-chave: COVID-19; Coronavírus; Odontologia; Biossegurança; Epidemia.

\section{Introdução}

ב $\mathrm{m} 8$ de janeiro de 2020, um novo Coronavírus foi oficialmente anunciado pelo Centro de Controle e Prevenção de Doenças da China como agente etiológico de uma nova doença respiratória em humanos. ${ }^{1}$ A epidemia teve início em 31 de dezembro de 2019, na cidade de Wuhan, província de Hubei na China, de onde as infecções se espalharam rapidamente para todo o mundo. Em 30 de janeiro de 2020, a Organização Mundial de Saúde (OMS) classificou a epidemia como u ma emergência de saúde pública de interesse internacional ${ }^{2} \mathrm{e}$ em 11 de março de 2020, foi oficialmente declarada a pandemia por SARSCoVID-2.No Brasil, o primeiro caso da doença foi notificado em 26 de fevereiro de 2020 e a transmissão comunitária foi reconhecida em 20 de março de $2020 .{ }^{3}$ Desde então, esta nova realidade tem impactado fortemente em todo arcabouço que estrutura as relações e a economia e impõe aos profissionais de saúde seu maior desafio sanitário dos últimos 100 anos. $^{4}$

Em virtude à proximidade com a face e à exposição à saliva, sangue e outros fluidos corporais, os cirurgiõesdentistas (CD) estão altamente expostos ao risco de infecção por SARS-CoVID-2 figurando no topo da lista entre as profissões de maior risco ocupacional..$^{5}$ Os policiais militares, da mesma forma, fazem parte do grupo de profissionais de serviços essenciais em meio à pandemia. Em virtude disso, enquanto fazem o trabalho de policiamento ostensivo, estão mais expostos e, consequentemente, também mais suscetíveis à contaminação pelo SARSCoVID-2. As unidades de saúde bucal na Polícia Militar do Estado do Rio de Janeiro (PMERJ) atendem entre policiais militares e seus dependentes, cerca de 9.516 pacientes ao mês, ${ }^{6} \mathrm{o}$ que demandará uma readequação do protocolo de controle de infecção empregado nos atendimentos odontológicos em tempos de COVID-19.

A revisão integrativa realizada neste artigo visou efetuar análises e sínteses do tema de interesse, possibilitando estabelecer conclusões gerais a respeito dos cuidados que devem ser tomados para o atendimento odontológico em tempos de COVID-19 e apontar lacunas do conhecimento a serem preenchidas com a realização de novos estudos a respeito. Ademais, a partir dessa revisão e das evidências científicas encontradas propor uma readequação do protocolo de atendimento odontológico para as unidades de saúde bucal da PMERJ durante a pandemia da COVID-19. 


\section{Material e Métodos}

A pergunta que moveu a pesquisa realizada nessa revisão foi: quais cuidados devem ser adotados no atendimento odontológico em tempos de COVID-19? A metodologia para a revisão integrativa obedeceu às seguintes fases: (1) estabelecimento da pergunta de investigação; (2) pesquisa de estudos relevantes; (3) seleção dos estudos baseada nos critérios de inclusão pré-estabelecidos; (4) análise e elaboração de dados; e (5) resumo e comunicação da informação. A partir dessa revisão foi reconstruído o protocolo de atendimento odontológico nas unidades de saúde bucal da PMERJ durante a pandemia da COVID-19.

A busca foi realizada em 11 de abril de 2020, nas bases: Portal Regional da Biblioteca Virtual em Saúde (BVS), que incorpora Lilacs, SciELO, Medline e outros tipos de fontes de informação tais como recursos educacionais abertos, sites de internet e eventos científicos, Web of Science e Pubmed. A estratégia de busca empregada incluiu: ("COVID-19" AND "dentistry"). Foi estipulado recorte temporal de publicações entre os anos de 2019 e 2020 e não foi estipulado recorte territorial. A busca foi realizada através do título, resumo e palavras-chave. Para inclusão ou exclusão dos documentos foram empregados os seguintes critérios: a) inclusão: documentos que abordavam o atendimento odontológico e a infecção por
COVID-19; estudos que apresentavam protocolos de cuidados para a prevenção da infecção da equipe de saúde ou infecção cruzada por COVID-19; b) exclusão: estudos que não descreveram as rotinas de biossegurança para prevenção de infecção do COVID-19 durante o atendimento da equipe de saúde; artigos não disponíveis em inglês, espanhol ou português e artigos não encontrados.

Com base na estratégia de busca adotada foram identificados 39 estudos. Destes, excluíram-se 8 que apresentavam duplicidade entre as bases. Os 31 títulos e resumos restantes foram lidos por dois revisores. Para os artigos cujos resumos indicavam possibilidade de seleção era obtida a versão integral, visando a confirmar a elegibilidade e a inclusão no estudo. Nos casos em que a leitura do resumo não fosse suficiente para estabelecer se o estudo deveria ser incluído, o artigo também era obtido e lido na íntegra para determinar sua elegibilidade. Dos 31 artigos restantes, após aplicação dos critérios de exclusão, 13 foram selecionados. Visando ampliar o escopo da análise para essa revisão, ${ }^{7}$ foram realizadas buscas manuais nas referências bibliográficas dos 13 artigos incluídos em busca de outros trabalhos que pudessem estar dentro dos critérios de inclusão adotados somando mais 5 outros artigos, totalizando 18 estudos que compuseram a base analisada neste artigo (Figura 1).

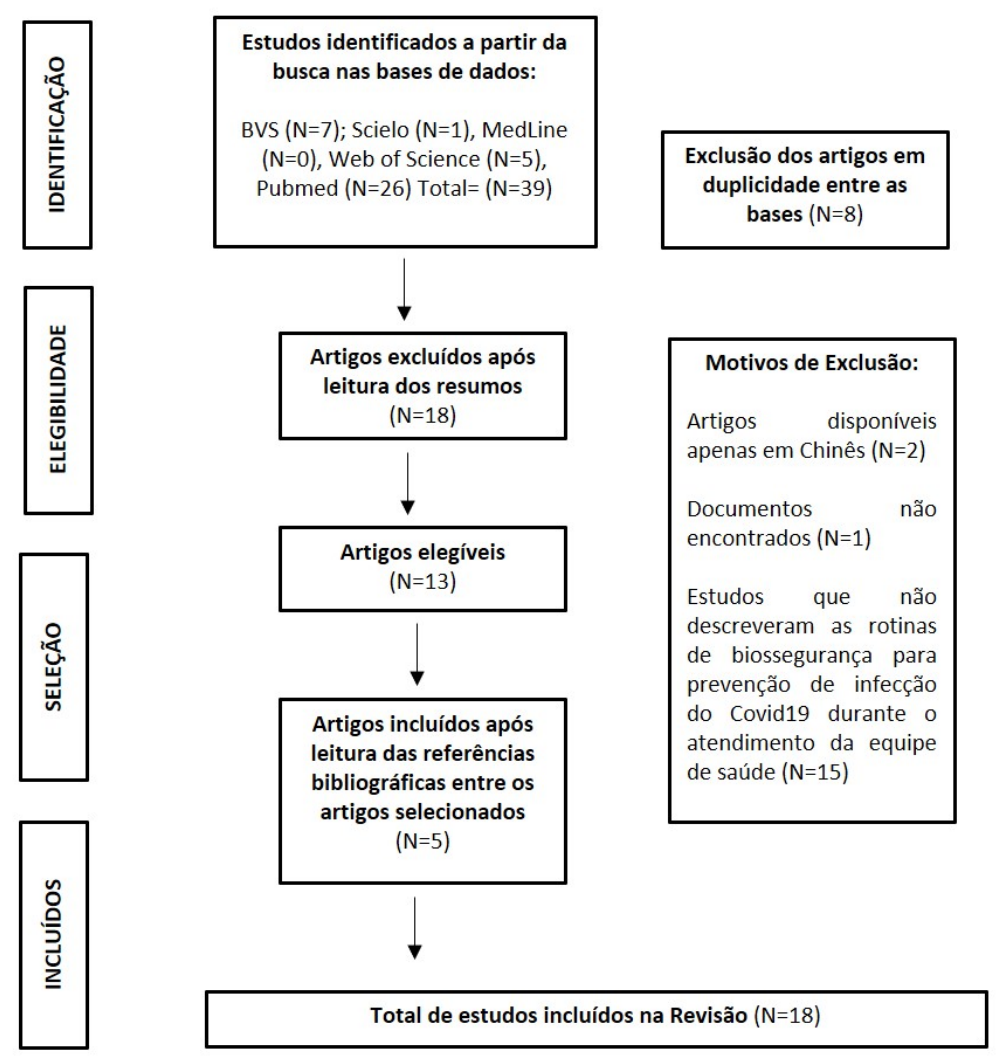

Figura 1. Fluxograma (Flowchart) da identificação e seleção dos artigos para revisão sobre os cuidados para o atendimento odontológico em tempos de COVID-19. (Abreviações: $\mathrm{N}=$ Número) 


\section{Resultados e Discussão}

A Tabela 1 permite verificar o país da publicação, o método utilizado, objetivos, resultados, conclusões e considerações sobre o atendimento odontológico em tempos de COVID-19 dos 18 artigos selecionados. Tais dados nortearam a descrição e discussão dos resultados deste artigo e respaldaram a construção da proposta de protocolo para os atendimentos odontológicos.

Tabela 1. Artigos identificados na revisão, segundo autor, ano de publicação, país, resultados, conclusão e medidas de prevenção durante o atendimento odontológico.

\begin{tabular}{|c|c|c|c|}
\hline Autor, ano e país & Métodos e Objetivos & Resultados e Conclusão & $\begin{array}{l}\text { Medidas de } \\
\text { do COVID-19 } \\
\text { odonenção de infocçãa } \\
\text { odonto o de }\end{array}$ \\
\hline $\begin{array}{l}\text { Adams e Walls, } \\
\text { 2020, EUA }\end{array}$ & $\begin{array}{l}\text { Artigo de opinião. Destacar a } \\
\text { necessidade de prevenção de } \\
\text { infecção cruzada. }\end{array}$ & $\begin{array}{l}\text { Recomendam a prioridade de testagem para } \\
\text { COVID-19 para os profissionais de saúde e } \\
\text { seus familiares e o apoio com alimentação } \\
\text { adequada e redução de ansiedade da } \\
\text { equipe. }\end{array}$ & $\begin{array}{l}\text { Recomendam o uso de EPI e higiene rigorosa } \\
\text { das mãos. }\end{array}$ \\
\hline $\begin{array}{l}\text { Berlin-Broner e } \\
\text { Levin, }{ }^{27} 2020 \text {, } \\
\text { Canadá }\end{array}$ & $\begin{array}{l}\text { Carta ao editor. Relatar as } \\
\text { prioridades de atendimento } \\
\text { odontológico nos tempos de } \\
\text { COVID-19. }\end{array}$ & $\begin{array}{l}\text { Importância da prevenção para evitar } \\
\text { emergências. Priorizam atendimento de } \\
\text { doenças agudas, mesmo na ausência de } \\
\text { dor. }\end{array}$ & - \\
\hline $\begin{array}{l}\text { Cochrane, }{ }^{30} 2020, \\
\text { Brasil }\end{array}$ & $\begin{array}{l}\text { Revisão bibliográfica. Indicar } \\
\text { a necessidade de fazer } \\
\text { revisões periódicas sobre } \\
\text { COVID-19. }\end{array}$ & - & $\begin{array}{l}\text { Lavagem das mãos, uso de EPI e precauções } \\
\text { gerais. }\end{array}$ \\
\hline $\begin{array}{l}\text { Guo et al, }{ }^{28} 2020, \\
\text { China }\end{array}$ & $\begin{array}{l}\text { Estudo observacional } \\
\text { descritivo. Analisar as } \\
\text { características demográficas } \\
\text { e as razões de procurar } \\
\text { o serviço de emergência } \\
\text { odontológica no período da } \\
\text { epidemia. }\end{array}$ & $\begin{array}{l}\text { Houve uma queda na procura do } \\
\text { atendimento no início da COVID-19 de } \\
38 \% \text {. Atendimentos por infecção dentária } \\
\text { oral aumentaram de } 51 \% \text { para } 71 \% \text { e por } \\
\text { trauma dental reduziram de } 14,2 \% \text { para } \\
10,5 \% \text {. A epidemia por COVID- } 19 \text { teve uma } \\
\text { grande influência no uso de serviços de } \\
\text { emergência odontológica. }\end{array}$ & $\begin{array}{l}\text { Indicam a restrição dos atendimentos } \\
\text { odontológicos para procedimentos de urgência } \\
\text { e emergência. }\end{array}$ \\
\hline $\begin{array}{l}\text { Kampf et al, }{ }^{18} 2020 \text {, } \\
\text { Alemanha }\end{array}$ & $\begin{array}{l}\text { Revisão bibliográfica. } \\
\text { Avaliar a persistência em } \\
\text { diferentes tipos de superfícies } \\
\text { inanimadas e testar a eficácia } \\
\text { de diferentes agentes } \\
\text { desinfetantes de superfície } \\
\text { contra vários tipos de } \\
\text { Coronavírus. }\end{array}$ & $\begin{array}{l}\text { Os Coronavírus humanos podem } \\
\text { permanecer infecciosos em superfícies } \\
\text { inanimadas por até } 9 \text { dias em temperatura } \\
\text { ambiente. A contaminação de superfícies } \\
\text { de toque frequente em unidades de } \\
\text { saúde representa uma via de transmissão } \\
\text { potencial. A clorexidina não se mostrou } \\
\text { eficaz. }\end{array}$ & $\begin{array}{l}\text { Lavagem das mãos. Desinfecção de superfícies } \\
\text { com hipoclorito de sódio de } 0,1 \% \text { ou etanol a } \\
62-71 \% \text { durante } 1 \text { minuto. }\end{array}$ \\
\hline $\begin{array}{l}\text { Khader et al, }{ }^{13} \\
\text { 2020, Arábia } \\
\text { Saudita }\end{array}$ & $\begin{array}{l}\text { Estudo observacional } \\
\text { analítico. Avaliar o grau } \\
\text { de conhecimento dos } \\
\text { CD da Jordânia sobre a } \\
\text { fisiopatologia do COVID-19 } \\
\text { e medidas de controle de } \\
\text { infecção durante tratamento } \\
\text { odontológico de pacientes } \\
\text { contaminados. }\end{array}$ & $\begin{array}{l}\text { A maioria dos CD estavam bem informados } \\
\text { acerca da fisiopatologia do COVID-19 } \\
\text { e das medidas de prevenção gerais na } \\
\text { clínica odontológica e apresentavam } \\
\text { menor compreensão sobre medidas de } \\
\text { proteção adicionais. Indicam } \\
\text { necessidade de guidelines regionais e } \\
\text { nacionais para dentistas. }\end{array}$ & $\begin{array}{l}\text { Higiene frequente das mãos; desinfecção } \\
\text { constante das superfícies; uso de EPI e troca dos } \\
\text { mesmos a cada paciente; aumentar a ventilação } \\
\text { da sala de atendimento. Uso de isolamento } \\
\text { absoluto, turbinas antirrefluxo e bochechos } \\
\text { antes do procedimento odontológico. }\end{array}$ \\
\hline $\begin{array}{l}\text { Khurshid et al, }{ }^{15} \\
2020, \text { Arábia } \\
\text { Saudita }\end{array}$ & $\begin{array}{l}\text { Artigo de opinião. Avaliar a } \\
\text { possibilidade de diagnóstico } \\
\text { precoce do COVID-19 através } \\
\text { da saliva. }\end{array}$ & $\begin{array}{l}\text { Necessidade de investigações adicionais da } \\
\text { importância da saliva em testes diagnósticos } \\
\text { e na transmissão da doença. }\end{array}$ & - \\
\hline $\begin{array}{l}\text { Martelli-Júnior et } \\
\text { al, }{ }^{25} 2020 \text {, Brasil }\end{array}$ & $\begin{array}{l}\text { Carta ao editor. Relatar a } \\
\text { importância das publicações } \\
\text { científicas neste momento de } \\
\text { Pandemia de COVID-19. }\end{array}$ & $\begin{array}{l}\text { Considerando o número significativo de CD } \\
\text { em todo o mundo, é necessário refletir } \\
\text { e agir rapidamente para melhor capacitá- } \\
\text { los no tratamento odontológico diante } \\
\text { dos desafios da pandemia de } \\
\text { COVID-19. }\end{array}$ & - \\
\hline $\begin{array}{l}\text { Meng et al, }{ }^{12} 2020 \text {, } \\
\text { China }\end{array}$ & $\begin{array}{l}\text { Relato de caso. A partir } \\
\text { da experiência vivenciada } \\
\text { sobre COVID-19 fornecer } \\
\text { protocolos de gestão para } \\
\text { CD e estudantes em áreas } \\
\text { afetadas. }\end{array}$ & $\begin{array}{l}\text { Os consultórios odontológicos podem } \\
\text { representar uma ameaça ao controle de } \\
\text { infecção da doença. } 29 \% \text { da população } \\
\text { infectada foi de profissionais de saúde em } \\
\text { Wuham. }\end{array}$ & $\begin{array}{l}\text { Restringir os atendimentos (urgência e } \\
\text { emergência). Limpeza da sala e desinfecção, } \\
\text { pacientes tratados em sala bem ventiladá } \\
\text { ou salas negativamente pressurizadas. Pré- } \\
\text { triagem (anamnese de rastreio) e verificação } \\
\text { da temperatura. Higiene rigorosa das mãos, } \\
\text { EPI para toda a equipe odontológica. Bochecho } \\
\text { com antisséptico, evitar procedimentos que } \\
\text { possam gerar aerossóis e uso de seringa tríplice, } \\
\text { evitar radiografias intraorais, uso de aspiração } \\
\text { adequada, de isolamento absoluto com lençol } \\
\text { de borracha quando possível, de fio } \\
\text { reabsorvível e atendimento a } 4 \text { mãos. }\end{array}$ \\
\hline
\end{tabular}




\begin{tabular}{|c|c|c|c|}
\hline $\begin{array}{l}\text { Napimoga e } \\
\text { Freitas, }{ }^{16} 2020, \\
\text { Brasil }\end{array}$ & $\begin{array}{l}\text { Comunicado. Fornecer uma } \\
\text { visão geral dos motivos para o } \\
\text { fechamento dos consultórios } \\
\text { dentários para tratamentos } \\
\text { eletivos e perspectivas futuras } \\
\text { desse cenário. }\end{array}$ & $\begin{array}{l}\text { Consultórios odontológicos são locais de } \\
\text { alto risco para transmissão. Os atendimentos } \\
\text { estão associados a produção de aerossol, } \\
\text { de saliva e sangue, que permanecem em } \\
\text { suspensão no ar durante longos períodos } \\
\text { de tempo e se depositam em superfícies do } \\
\text { ambiente por até } 9 \text { dias. }\end{array}$ & $\begin{array}{l}\text { Recomendam: higiene rigorosa das mãos, } \\
\text { medidas de proteção individual para } \\
\text { os profissionais da área odontológica, } \\
\text { enxaguatório bucal antes dos procedimentos } \\
\text { odontológicos, isolamento com dique de } \\
\text { borracha, turbinas antirrefluxo, desinfecção } \\
\text { do consultório dentário (hipoclorito de sódio } \\
\text { a } 0,1 \% \text { e álcool a } 70 \% \text { ), máscara cirúrgica, } \\
\text { proteção ocular com protetores faciais e } \\
\text { gerenciamento correto de resíduos médicos. }\end{array}$ \\
\hline $\begin{array}{l}\mathrm{Ng} \mathrm{K} \text {, et al, }{ }^{20} 2020 \\
\text { Singapura }\end{array}$ & $\begin{array}{l}\text { Relato de caso. Descrever } \\
\text { o desfecho clínico dos } \\
\text { profissionais de saúde que } \\
\text { cuidaram de um paciente } \\
\text { com pneumonia grave antes } \\
\text { do diagnóstico de COVID-19. }\end{array}$ & $\begin{array}{l}\text { Nenhum profissional de saúde que teve } \\
\text { contato com esse paciente foi contaminado. }\end{array}$ & $\begin{array}{l}\text { Indicam o uso da máscara N95 e a lavagem } \\
\text { correta das mãos entre outros procedimentos } \\
\text { de controle de infecção. }\end{array}$ \\
\hline $\begin{array}{l}\text { Peng et al, }{ }^{5} 2020 \text {, } \\
\text { China }\end{array}$ & $\begin{array}{l}\text { Revisão de } \begin{array}{r}\text { literatura. } \\
\text { Recomendar }\end{array} \text { medidas } \\
\text { de controle de infecção } \\
\text { visando a prevenção da } \\
\text { infecção cruzada na prática } \\
\text { odontológica. }\end{array}$ & $\begin{array}{l}\text { Os profissionais de odontologia } \\
\text { apresentam grande risco de infecção } \\
\text { pelo COVID-19. Medidas de controle de } \\
\text { infecção são fundamentais para prevenir a } \\
\text { transmissão cruzada em hospitais e clínicas } \\
\text { odontológicas. }\end{array}$ & $\begin{array}{l}\text { Triagem prévia (temperatura e história clínica), } \\
\text { higiene das mãos, uso de EPI, bochecho com } \\
\text { enxaguatório antes do atendimento (peróxido } \\
\text { de hidrogênio a } 1 \% \text { ou povidona a } 0,2 \% \text { ), } \\
\text { isolamento absoluto com dique de borracha, } \\
\text { priorizar uso de instrumentos manuais para } \\
\text { minimizar a geração de aerossol, uso de } \\
\text { motores com função antirrefluxo, desinfecção } \\
\text { do ambiente clínico e adequada gestão dos } \\
\text { resíduos odontológicos. }\end{array}$ \\
\hline $\begin{array}{l}\text { Sabino-Silva et al, }{ }^{11} \\
\text { 2020, Canadá/Brasil }\end{array}$ & $\begin{array}{l}\text { Artigo de opinião. Avaliar a } \\
\text { possibilidade de diagnóstico } \\
\text { precoce do COVID-19 através } \\
\text { da saliva. }\end{array}$ & $\begin{array}{l}\text { Possibilidade de coleta da saliva para } \\
\text { estudos diagnósticos, como técnica mais } \\
\text { simples, com menor desconforto e menor } \\
\text { risco ocupacional. }\end{array}$ & $\begin{array}{l}\text { Higiene das mãos, uso de EPI, cautela ao realizar } \\
\text { procedimentos geradores de aerossol. }\end{array}$ \\
\hline $\begin{array}{l}\text { Sohrabi et al, } \\
\text { 2020, Reino Unido }\end{array}$ & $\begin{array}{l}\text { Revisão de literatura. Revisar } \\
\text { os conhecimentos atuais } \\
\text { acerca do COVID-19. }\end{array}$ & $\begin{array}{l}\text { Mais pesquisas são necessárias para } \\
\text { esclarecer as formas de transmissão e o } \\
\text { desenvolvimento de vacinas. }\end{array}$ & $\begin{array}{l}\text { Higiene frequente das mãos, identificação e } \\
\text { isolamento de pessoas com histórico de viagem } \\
\text { recente a países de risco. }\end{array}$ \\
\hline $\begin{array}{l}\text { Spagnuolo et al, }{ }^{14} \\
2020, \text { Itália }\end{array}$ & $\begin{array}{l}\text { Editorial. Fornecer uma } \\
\text { visão geral do COVID-19 e } \\
\text { odontologia. }\end{array}$ & $\begin{array}{l}\text { Necessidade de diretrizes de prevenção } \\
\text { e controle da COVID-19 no atendimento } \\
\text { odontológico. }\end{array}$ & $\begin{array}{l}\text { Atender apenas emergências ou urgências, } \\
\text { distanciamento social, aferir temperatura e } \\
\text { aplicar questionário de rastreio para COVID-19, } \\
\text { uso de EPI, uso de antissépticos antes da } \\
\text { realização do atendimento odontológico, } \\
\text { minimizar produção de aerossol, uso de motores } \\
\text { com função antirrefluxo, limpeza de todas as } \\
\text { superfícies, ventilar área de atendimento e } \\
\text { desinfecção do sistema de ar condicionado. }\end{array}$ \\
\hline $\begin{array}{l}\text { Schwartz et al, }{ }^{22} \\
\text { 2020, EUA e Taiwan }\end{array}$ & $\begin{array}{l}\text { Relato de caso. Analisar as } \\
\text { lições aprendidas durante a } \\
\text { epidemia do SARS-Cov1 em } \\
\text { Taiwan quanto às medidas de } \\
\text { proteção do trabalhador de } \\
\text { saúde, estendendo-as para o } \\
\text { COVID-19. }\end{array}$ & $\begin{array}{l}\text { Recomendam a criação de áreas com risco } \\
\text { estratificado para fluxo de pessoas. Zona } \\
\text { limpa para triagem, zona intermediária } \\
\text { para casos suspeitos ou atípicos e } \\
\text { zona contaminada para pacientes com } \\
\text { diagnóstico confirmado. }\end{array}$ & $\begin{array}{l}\text { Recomendam que a cada ponto de transição } \\
\text { sejam adotados os protocolos de higiene das } \\
\text { mãos e uso do EPI mais completo de acordo } \\
\text { com a estratificação do risco. }\end{array}$ \\
\hline $\begin{array}{l}\text { Yang et al, }{ }^{17} 2020, \\
\text { China }\end{array}$ & $\begin{array}{l}\text { Relato de caso. Descrever a } \\
\text { experiência do departamento } \\
\text { de cirurgia oral e maxilofacial } \\
\text { nas medidas de prevenção e } \\
\text { controle. }\end{array}$ & $\begin{array}{l}\text { Apresentam algoritmo de diagnóstico e } \\
\text { tratamento de pacientes categorizados } \\
\text { de acordo com a urgência, severidade da } \\
\text { doença e tipo de intervenção. }\end{array}$ & $\begin{array}{l}\text { Atendimento somente de emergências } \\
\text { e urgências, avaliação do risco infecção } \\
\text { COVID-19. Evitar transporte desnecessário do } \\
\text { paciente. Quartos individuais com pias para } \\
\text { lavagem das mãos, bem ventilados, portas } \\
\text { fechadas o tempo inteiro, entrada e saída } \\
\text { mínima. Visitação limitada. Realizar exames } \\
\text { complementares conforme necessidade. As } \\
\text { cirurgias devem ser realizadas em centro } \\
\text { cirúrgico em salas com pressão negativa. Uso } \\
\text { de spray de hipoclorito de sódio a } 3 \% \text { durante } \\
30 \text { minutos para desinfecção do ambiente de } \\
\text { trabalho (centro cirúrgico). }\end{array}$ \\
\hline $\begin{array}{l}\text { Zhang et al, }{ }^{26} 2020 \text {, } \\
\text { China }\end{array}$ & \begin{tabular}{lcc} 
Editorial. & \multicolumn{2}{c}{ Descrever a } \\
experiência da & resposta \\
hospitalar em & Shangai \\
(China) durante o surto da \\
epidemia.
\end{tabular} & $\begin{array}{l}\text { Implementaram uma infraestrutura } \\
\text { com áreas para triagem de pacientes } \\
\text { com COVID-19, sem relatos de infecção } \\
\text { hospitalar. }\end{array}$ & $\begin{array}{l}\text { Enfatizam a importância do pré-atendimento } \\
\text { para diminuir a infeçãa cruzada: checagem da } \\
\text { temperatura, história clínica, desinfecção das } \\
\text { mãos, isolamento de pacientes com infecção } \\
\text { confirmada. }\end{array}$ \\
\hline
\end{tabular}


O novo Coronavírus pertence à família dos Coronaviridae, da ordem Nidovirais. São vírus que possuem um genoma grande, composto por RNA de fita simples, com polaridade positiva e nucleocapsídeo helicoidal. ${ }^{89}$ Atualmente, existem quatro gêneros de Coronavírus, a maioria pode causar doenças infecciosas com repercussões leves, moderadas ou graves no trato respiratório em humanos e vertebrados, tais como o Coronavírus da síndrome respiratória aguda grave (SARS-CoV) (2002-2003) e o Coronavírus da síndrome respiratória do médio oriente (MERS-CoV) (2012). Entretanto, o novo SARS-CoVID-2 diferencia-se por seu maior potencial de contágio e consequentemente rápida propagação. ${ }^{10}$

Com relação às vias de transmissão interpessoal, há um consenso entre os autores que ocorre por meio de gotículas respiratórias produzidas quando uma pessoa tosse ou espirra e através de contato. ${ }^{5,8,11-18} \mathrm{O}$ vírus foi encontrado na saliva $a^{5,8,11-15,19}$ e a transmissão por aerossóis também foi relatada, ${ }^{5,11,12,14,16,17,20}$ o que representa uma grande preocupação para os $\mathrm{CD}$ já que muitos dos procedimentos realizados por estes profissionais são geradores de aerossol. No que se refere ao tempo de incubação, ela ocorre entre 5 a 6 dias, ${ }^{12,13,16,19}$ podendo se estender por até
14 dias. $^{5,12,13,16,19}$ A ocorrência da transmissão durante o período de incubação ${ }^{21}$ e em pacientes assintomáticos ${ }^{5,11,12,14,16,22,23,24}$ é de muita relevância na prática odontológica já que o paciente assintomático apresenta carga viral semelhante aos pacientes com manifestações clínicas. ${ }^{24}$ Este fato demonstra a necessidade do CD aderir a rígidos protocolos de proteção em todos os pacientes, incluindo os que não apresentam sintomas.

A apresentação clínica da SARS-CoVID-2 foi variada nos artigos analisados. Os sintomas mais comumente relatados foram febre e tosse, ${ }^{5,11,12,13,17,25,26}$ seguidos por mialgia, diarreia e vômitos, ${ }^{5,12,13}$ pneumonia ${ }^{4,5,11-13,15,16,17,18,25}$ e achados anormais na tomografia de tórax. ${ }^{12,17}$ Alguns pacientes podem ser totalmente assintomáticos..$^{5,11,12,14,16,22,23} \mathrm{~A}$ idade avançada $\mathrm{e}$ existência de comorbidades subjacentes tais como diabetes, hipertensão e doença cardiovascular foram associadas ao pior prognóstico da evolução da doença. ${ }^{12}$

O elevado risco ocupacional dos trabalhadores de saúde foi destacado em inúmeros estudos. ${ }^{4,5,11-16,17,20,22,23,25}$ Em virtude disso, medidas de prevenção para controle da infecção da COVID-19 foram sumarizadas para elaboração de protocolo de atendimento odontológico. (Quadro 1).

Quadro 1. Protocolo de atendimento odontológico

\section{PROTOCOLO DE ATENDIMENTO ODONTOLÓGICO}

Apenas atendimentos de emergência e urgência conforme indicação do CFO. Atendimento ambulatorial suspenso.

Pré-triagem dos pacientes na área externa da unidade de atendimento: Manter distância de 1,5 metros do paciente. Realizar anamnese para rastreio de COVID-19. Aferir temperatura do paciente.

Preparo do paciente para atendimento: encaminhar o paciente ao escovódromo para higiene das mãos e rosto (água, sabão e álcool gel) e bochecho por 30 segundos com peróxido de hidrogênio a $1 \%$.

Preparo da sala de atendimento: a bancada deve ter o mínimo de objetos. Seringa tríplice, alça do refletor e braço da cadeira com barreira (sacos plásticos ou filme plástico). Micromotores e canetas de alta rotação devem ser esterilizados a cada atendimento. Prontuário e celulares não devem ficar na sala de atendimento.

Sequência de paramentação do dentista e auxiliar: retirar todos os adereços (anéis, pulseiras, cordões, brincos e relógios), lavar mãos e rosto com água e sabão por 20 segundos antes da paramentação com gorro, máscara cirúrgica, óculos de proteção, viseira facial, avental longo de manga comprida impermeável com fechamento posterior e luva de procedimento. Em procedimentos nos quais serão gerados aerossóis, a máscara de escolha é a N95 ou PFF2 e sobre essa, uma máscara cirúrgica.

Atendimento a 4 mãos: evitar a utilização da seringa tríplice, caneta de alta rotação e ultrassom. Manter aspiração constante e eficiente. Evitar a realização de radiografias periapicais. Dar preferência a instrumentos manuais para remoção de cáries e cálculo.

Retirada do EPI: retirar as luvas, o protetor facial, as máscaras por suas tiras ou elásticos, retirar o avental e gorro. Passar álcool em gel nas mãos a cada etapa. Lavar as mãos, face e pescoço com água e sabão por 30 segundos.

Sobre o resíduo gerado no tratamento: deverá ser descartado em lixo infeccioso.

Limpeza e desinfecção de superfícies: abrir janelas para ventilar o ambiente de trabalho e para procedimentos em que foi gerado aerossol, aguardar 3 horas para limpeza do ambiente, realizar desinfecção rigorosa de todo o consultório com Hipoclorito de Sódio a $0,1 \%$ ou álcool a $70 \%$ e trocar as barreiras de proteção a cada paciente. 
A recomendação da suspensão dos procedimentos odontológicos eletivos foi citada em 8 trabalhos. ${ }^{5,12,14,16,17,27,28}$ As situações que configuram emergência e urgência odontológica estão disponíveis no site do Conselho Federal de Odontologia (CFO).$^{29}$ Sabendo que o Brasil é um país de dimensões continentais e com particularidades regionais expressivas, é recomendável que o $\mathrm{CD}$ esteja atento às informações sobre a evolução da doença no seu âmbito loco-regional. Tais relatórios são publicados pelas subsecretarias de vigilância em saúde estaduais e municipais.

Os procedimentos de triagem prévia ao atendimento de urgência/emergência são amplamente recomendados ${ }^{5,12,14,16,17} \mathrm{e}$ devem incluir perguntas para rastreio da COVID-19 (Quadro 2). Caso o paciente tenha respondido sim em pelo menos uma das perguntas, recomenda-se adiar o tratamento odontológico por 14 dias, mesmo na ausência de sintomas respiratórios. ${ }^{5,12,17}$

Quadro 2. Questionário de rastreio para COVID-19

\section{QUESTIONÁRIO TRIAGEM}

1. Teve febre ou sintomas respiratórios nos últimos 14 dias?

2. Teve contato próximo com pessoas que testaram positivo para a Covid-19 ou tiveram febre ou sintomas respiratórios nos últimos 14 dias?

A utilização de bochechos antissépticos para reduzir a carga microbiana antes do atendimento odontológico foi citada em alguns estudos, ${ }^{5,12-14,16}$ no entanto, parece existir controvérsias no que concerne a substância a ser utilizada. Nesta revisão, apenas um dos autores ${ }^{5}$ faz menção ao tema, citando as instruções das Diretrizes de diagnóstico e tratamento da COVID-19 lançada pela Comissão Nacional de Saúde da China, que defende o uso de bochechos com Peróxido de Hidrogênio a $1 \%$ ou Iodopovidona a $0,2 \%$. A recomendação do uso do peróxido de hidrogênio é baseada na eficácia que este agente apresenta na descontaminação de superfícies, ${ }^{18}$ no entanto, ainda não há evidência científica comprovando sua eficácia na diminuição da carga viral quando utilizada como bochecho. A clorexidina, comumente utilizada como bochecho antisséptico em odontologia, não se mostrou efetiva na descontaminação de superfícies infectadas pelo SARS-CoVID-2 ${ }^{18}$ e por esta razão, sua utilização não está sendo recomendada no protocolo de atendimento. ${ }^{5}$

Medidas para evitar a produção de aerossóis durante o atendimento são citadas e incluem evitar a utilização da seringa tríplice, caneta de alta rotação e ultrassom preferindo o uso de instrumentos manuais para remoção de cálculo e cáries, ${ }^{5,12,13,16}$ auxiliados pelo uso do isolamento absoluto e sugadores de alta potência. Radiografias periapicais devem ser evitadas pois estimulam secreção salivar e tosse. ${ }^{12}$

Quanto à prevenção da infecção cruzada em trabalhadores de saúde, recomenda-se a higienização das mãos e uso de Equipamentos de Proteção Individual (EPI). 5,11-14,16,17,20,22,23,30

As máscaras N95/PFF2 são recomendadas ${ }^{4,12,20,22,23,31,32}$ devido a melhor eficácia de filtração e vedação quando comparadas às máscaras cirúrgicas descartáveis. ${ }^{33}$ Essas máscaras são consideradas semi descartáveis, podendo ser reutilizadas pelo mesmo usuário enquanto permanecerem em boas condições de uso (boa vedação, tirantes elásticos íntegros, sem evidência de sujidade ou contaminação por fluidos corpóreos). ${ }^{33}$ Devido à crise de abastecimento de EPI causada pela pandemia, tem sido recomendado, ${ }^{32,34}$ o uso destas máscaras por período superior ao prazo recomendado pelo fabricante, desde que observadas as boas condições de uso. ${ }^{34}$ Uma vez colocada, a manipulação das máscaras N95/PFF2 deverá sempre ser feita pelas tiras, nunca tocando a superfície externa, que é considerada contaminada. Após retirada, a máscara deve ser acondicionada em embalagem individual não hermética, de forma a permitir a saída de umidade.$^{33} \mathrm{O}$ uso de máscaras cirúrgicas sobrepostas a N95/PFF2 ajuda a prolongar a vida útil destas, ${ }^{33}$ reduzindo a possibilidade de sujidade, sendo recomendável em cirurgias ou no atendimento de pacientes sintomáticos.

É recomendado o uso de aventais/capotes em tecido não tecido (TNT) com gramatura mínima de $30 \mathrm{~g} / \mathrm{m}^{2}$, impermeável, com mangas longas, punho de malha ou elástico e abertura posterior. ${ }^{32}$ Recomenda-se descarte após cada atendimento, seguido por higiene das mãos. O uso de aventais plásticos de manga longa com abertura posterior sobrepostos ao avental de TNT, podem dispensar o descarte do avental de TNT após cada atendimento, podendo ser uma solução alternativa devido à dificuldade de compra de insumos gerada pela pandemia. O avental de plástico poderá ser reutilizado em outros atendimentos após realizada a desinfecção da superfície.

A proteção da mucosa conjuntival deve ser feita mediante o uso de óculos de proteção ou protetores faciais. ${ }^{5,16,17,23}$ Os protetores faciais são recomendados para procedimentos geradores de aerossol por fornecerem uma cobertura mais ampla, porém não dispensam a utilização da máscara ${ }^{32} \mathrm{e}$ devem sofrer processo de limpeza e desinfecção após cada atendimento. $^{32}$

Por fim, a limpeza da área de trabalho é uma medida fundamental para o controle de infecção cruzada $^{5,12-15,17,18,22} \mathrm{e}$ deve ser realizada ao final de cada atendimento. A desinfecção deve incluir todo equipamento, bancadas, cadeira, mesas e maçanetas. ${ }^{18}$ Estudos de persistência realizados em diferentes tipos de superfícies, demonstraram que algumas espécies de Coronavírus podem permanecer infectantes por até 9 dias em fômites. ${ }^{18}$ O SARS-CoVID-2 pode permanecer viável e infeccioso em aerossóis durante 3 horas, ${ }^{35}$ o que justifica a recomendação do protocolo de ventilar a sala de trabalho após cada atendimento ${ }^{14}$ e aguardar 3 horas para realização da limpeza da mesma. Álcool 70 ((álcool etílico hidratado $70^{\circ}$ INPM (Instituto Nacional de Pesos e Medidas) $/ 70^{\circ}$ INPM ((70\% p/p) ou $77^{\circ} \mathrm{GL}(77 \%$ v/v)). e Hipoclorito de Sódio a 
$0,1 \%$ foram as soluções de desinfecção citadas e consideradas eficazes para inativação do vírus mediante processo de friç̧ão. ${ }^{16,18}$

Como qualquer trabalho científico, este tem limitações. Algumas são fragilidades metodológicas provenientes dos artigos revisados, já que a maioria dos estudos foram na verdade relatos de sua experiência local de atendimento, sem, contudo, a testagem da eficiência das técnicas adotadas, o que dificultou o estabelecimento de evidências, além do reduzido número de publicações que relacionam a odontologia ao SARS-CoVID-2.

Por se tratar de um novo vírus em que as descobertas de suas especificidades acontecem no transcurso da pandemia, espera-se que novas publicações apontem para evidências que inevitavelmente demandarão mudanças nos protocolos de controle de infecção no atendimento odontológico.

\section{Conclusão}

Em períodos de surtos epidêmicos da SARS-CoVID-2, apenas os atendimentos de urgência e emergência odontológica devem ser realizados. $\mathrm{O} C \mathrm{CD}$ deve estar atento à higiene rigorosa das mãos e ao uso correto de todo EPI. Recomenda-se ainda a realização da triagem para rastreio da COVID-19, o bochecho prévio ao atendimento com peróxido de hidrogênio a $1 \%$ por 30 segundos, o trabalho à quatro mãos, a escolha sempre que possível de técnicas que não gerem aerossol, o uso de lençol de borracha e de aspiração eficiente. Deve ser respeitado o tempo de 3 horas entre os atendimentos quando houver produção de aerossol e realizada a higienização de todas as superfícies do consultório com hipoclorito de sódio a $0,1 \%$ ou álcool 70 entre cada paciente. Todo instrumental utilizado no atendimento deve ser esterilizado e os resíduos descartados de forma apropriada.

\section{Referências}

1. Li Q, Guan X, Wu P, Wang X, Zhou L, Tong Y, et al. Early transmission dynamics in Wuhan, China, of novel coronavirus-infected pneumonia. $\mathrm{N}$ Engl J Med. 2020;382(13):1199-1207.

2. Mahase E. China coronavirus: WHO declares international emergency as death toll exceeds 200. BMJ. 2020; 368:m408.In Press 2020.

3. Ministério da Saúde, [homepage na internet]. Portaria 454. 20 marc. 2020 [acesso em 12 abr 2020]. Disponível em: https://www.saude.gov.br/boletinsepidemiologicos.

4. Farooq I, Ali S. COVID-19 outbreak and its monetary implications for dental practices, hospitals and healthcare workers. Postgrad Med J. In Press 2020.

5. Peng X, Xu X, Li Y, Cheng L, Zhou X, Ren B. Transmission routes of 2019 $\mathrm{nCoV}$ and controls in dental practice. Int J Oral Sci. 2020; 12(1):1-6.

6. Consulta à Diretoria Geral de Odontologia, PMERJ, em 15 de abril de 2020 sobre os atendimentos em 2019.

7. Mendes KDS, Silveira RCCP, Galvão CM. Revisão integrativa: método de pesquisa para a incorporação de evidências na saúde e na enfermagem. Texto Contexto Enferm. 2008; 17(4):758-764.

8. Sohrabi, C., Alsafi, Z., O’Neill, N., Khan, M., Kerwan, A., Al-Jabir, A. et al. World Health Organization declares global emergency: A review of the 2019 novel coronavirus (COVID-19). Int J Surg. 2020; 76:71-76.

9. Mizumoto, K., Chowell, G. Transmission potential of the novel coronavirus (COVID-19) onboard the diamond Princess Cruises Ship, 2020. Inf Dis Mod. 2020;5:264-270.

10. Zhou P, Yang XL, Wang XG, Hu B, Zhang L, Zhang W, et al. A pneumonia outbreak associated with a new coronavirus of probable bat origin. Nature. 2020; 579:270-273.

11. Sabino-Silva R, Jardim ACG, Siqueira WL. Coronavirus COVID-19 impacts to dentistry and potential salivary diagnosis. Clin Oral Investig. 2020;24(4):1619-1621.

12. Meng L, Hua F, Bian Z. Coronavirus disease 2019 (COVID-19): Emerging and future challenges for Dental and Oral Medicine. J Dent Res. In Press 2020. 13. Khader Y, Al Nsour M, Al-Batayneh OB, Saadeh R, Bashier H, Alfaqih M, et al. Dentists awareness, perception, and attitude regarding COVID-19 and infection control: A cross-sectional study among Jordanian dentists. JMIR Public Health Surveill. 2020; 6(2):e18798.

14. Spagnuolo G, De Vito D, Rengo S, Tatullo M. COVID-19 Outbreak: An overview on dentistry. Int. J. Environ. Res. Public Health. 2020;17(6):2094.

15. Khurshid Z, Asiri FYI, Al Wadaani H. Human Saliva: Non-invasive fluid for detecting novel coronavirus (2019-nCoV). Int. J. Environ. Res. Public Health. 2020;17(7): E2225.

16. Napimoga MH, Freitas ARR. Dentistry vs severe acute respiratory syndrome coronavirus 2: How to face this enemy. RGO. 2020;68:E20200011. 17. Yang Y, Soh HY, Cai ZG, Peng X, Zhang Y, Guo CB. Experience of diagnosing and managing patients in Oral Maxillofacial Surgery during the prevention and control period of the new coronavirus pneumonia. Chin J
Dent Res. 2020;23(1):57-62.

18. Kampf G, Todt D, Pfaender S, Steinmann. E. Persistence of coronaviruses on inanimate surfaces and their inactivation with biocidal agents. J Hosp Infect. 2020; 104(3):246-251.

19. Pan X, Ojcius DM, Gao TG, Li Z, Pan C, Pan C. Lessons learned from the 2019-nCoV epidemic on prevention of future infectious diseases. Microbes Infect. 2020;22(2): 86-91.

20. Ng K, Poon BH, Kiat Puar TH, Shan Quah JL, Loh WJ, Wong YJ, et al. COVID-19 and the risk to health care workers: A case report. Ann Intern Med. 2020;L20-0175.

21. Rothe C, Schunk M, Sothmann P, Bretzel G, Froeschl G, Wallrauch C, et al. Transmission of 2019-nCoV infection from an asymptomatic contact in Germany. N Engl J Med. 2020; 382(10):970-971.

22. Schwartz J, King CC, Yen MY. Protecting healthcare workers during the coronavirus disease 2019 (COVID-19) outbreak: Lessons from Taiwan's severe acute respiratory syndrome response. Clin Infect Dis. 2020; ciaa 255.

23. Adams JG.; Walls, RM. Supporting the health care workforce during the COVID-19 global epidemic. JAMA. 2020;Published Online.

24. Zou L, Ruan F, Huang M, Liang L, Huang H, Hong Z, et al. SARS-CoV-2 viral load in upper respiratory specimens of infected patients. N Engl J Med. 2020;382(12):1177-1179.

25. Martelli-Júnior H, Machado RA, Martelli DRB, Coletta RD. Dental journals and coronavirus disease (COVID-19): A current view. Oral Oncol. $2020 ; 104664$

26. Zhang Y, Sun Z, Latour JM, Hu B, Qian J. Hospital response to the COVID-19 outbreak: the experience in Shanghai, China. J Adv Nurs. 2020; In Press 2020.

27. Berlin-Broner Y, Levin L. 'Dental hierarchy of needs' in the COVID-19 era-or why treat when it doesn't hurt? Oral Health Prev Dent. 2020; 18(2):95. 28. Guo H, Zhou Y, Liu X, Tan J. The impact of the COVID-19 epidemic on the utilization of emergency dental services. J Dent Sci. In press 2020.

29. Conselho Federal de Odontologia, [homepage na internet]. [acesso em 13 abr 2020]. Disponível em: https://coronavirus.cfo.org.br/ 2020.

30. Cochrane, Coleção especial: Coronavirus (COVID-19): medidas para o controle e a prevenção de infecções. https://www.cochrane.org/pt/ special-collection-coronavirus-covid-19-infection-control-and-preventionmeasures.

31. CDC. Interim infection prevention and control recommendations for patients with suspected or confirmed coronavirus disease 2019 (COVID-19) in healthcare settings. (atualizada em 13/04/2020). Disponível em: https://www.cdc.gov/coronavirus/2019-ncov/hcp/infection-control recommendations.html?CDC_AA_refVal=https $\% 3 \mathrm{~A} \% 2 \mathrm{~F} \% 2 \mathrm{Fwww} . \mathrm{cdc}$. gov $\% 2$ Fcoronavirus $\% 2$ F 2019 -ncov $\% 2$ Finfection-control $\% 2$ Fcontrolrecommendations.html

12020 .

32. ANVISA. NOTA TÉCNICA No 04/2020. Orientações para serviços 
de saúde: medidas de prevenção e controle que devem ser adotadas durante a assistência aos casos suspeitos ou confirmados de infecção pelo novo Coronavírus (SARS-COV-2). (Atualizada em 21/03/2020). Disponível em: http://portal.anvisa.gov.br/documents/33852/271858/ Nota+T\%C3\%A9cnica+n+04-2020+GVIMS-GGTES-ANVISA/ab5986603de4-4f14-8e6f-b9341c196b28/2020.

33. ANVISA. Cartilha de Proteção Respiratória contra Agentes Biológicos para Trabalhadores de Saúde. Disponível em: http://www.lacen.saude.pr.gov. br/arquivos/File/Manuais/Anexos/ANEXO_9_CARTILHA_PROTECAO_
RESPIRATORIA_CONTRA_AGENTES_BIOLOGICOS_PARA_ TRABALHADORES_SAUDE.pdf/2009.

34. CDC. Recommended Guidance for Extended Use and Limited Reuse of N95 Filtering Facepiece Respirators in Healthcare Settings. (Atualizada em 27/03/2020). Disponível em: https://www.cdc.gov/niosh/topics/hcwcontrols/ recommendedguidanceextuse.html/ 2020.

35. Van Doremalen N, Bushmaker T, Morris DH, Holbrook MG.; Gamble A; Williamson, B, et al. Aerosol and surface stability of SARS-CoV-2 as compared with SARS-CoV-1. N. Engl. J Med. 2020; 382(16):1564-1567.

\section{Minicurrículo e Contribuição dos Autores}

1. Adriane Batista Pires Maia - Cirurgiã Bucomaxilofacial; Doutoranda em Ciências da Saúde. Contribuição: Levantamento bibliográfico, preparo, redação e revisão do artigo ORCID: 0000-0001-6081-707X

2. Vanessa Paiva Reis - Cirurgiã Bucomaxilofacial; Estomatologista. Contribuição: Preparo, redação e revisão do artigo. ORCID: 0000-0001-7682-547X

3. Adriana Raymundo Bezerra - Cirurgiã Bucomaxilofacial; Mestre em Odontologia. Contribuição: preparo, redação e revisão do artigo. ORCID: 0000-0001-9487-1904

4. Danielle Castex Conde - Cirurgiã-Dentista; Doutora em Patologia Oral. Contribuição: Preparo, redação e revisão do artigo. ORCID: 0000-0002-8492-9145

Submetido: 21/04/2020 / Aceito para publicação: 25/04/2020

Autor correspondente

Adriane Batista Pires Maia

E-mail: adrianepmaia@gmail.com 